\section{Modeling and transportation planning for US noncombatant evacuation operations in South Korea}

\author{
John A. Kearby, Ryan D. Winz, Thom J. Hodgson, Michael G. Kay, \\ Russell E. King and Brandon M. McConnell \\ Operations Research Graduate Program and the Center for Additive Manufacturing \\ and Logistics, North Carolina State University, Raleigh, North Carolina, USA
}

Modeling and transportation planning

Received 28 May 2019 Revised 27 August 2019 13 October 2019

15 November 2019 Accepted 20 November 2019

\begin{abstract}
Purpose - The purpose of this paper is to investigate US noncombatant evacuation operations (NEO) in South Korea and devise planning and management procedures that improve the efficiency of those missions.

Design/methodology/approach - It formulates a time-staged network model of the South Korean noncombatant evacuation system as a mixed integer linear program to determine an optimal flow configuration that minimizes the time required to complete an evacuation. This solution considers the capacity and resource constraints of multiple transportation modes and effectively allocates the limited assets across a time-staged network to create a feasible evacuation plan. That solution is post-processed and a vehicle routing procedure then produces a high resolution schedule for each individual asset throughout the entire duration of the NEO.

Findings - This work makes a clear improvement in the decision-making and resource allocation methodology currently used in a NEO on the Korea peninsula. It immediately provides previously unidentifiable information regarding the scope and requirements of a particular evacuation scenario and then produces an executable schedule for assets to facilitate mission accomplishment.
\end{abstract}

Originality/value - The significance of this work is not relegated only to evacuation operations on the Korean peninsula; there are numerous other NEO and natural disaster related scenarios that can benefit from this approach.

Keywords Korea, Noncombatant evacuation, Time-staged network, US Military,

Vehicle routing procedure

Paper type Research paper

(C) John A. Kearby, Ryan D. Winz, Thom J. Hodgson, Michael G. Kay, Russell E. King and Brandon M. McConnell. Published in Journal of Defense Analytics and Logistics. Published by Emerald Publishing Limited. This article is published under the Creative Commons Attribution (CC BY 4.0) licence. Anyone may reproduce, distribute, translate and create derivative works of this article (for both commercial and non-commercial purposes), subject to full attribution to the original publication and authors. The full terms of this licence may be seen at http://creativecommons.org/licences/by/4.0/legalcode

Disclaimer: The views expressed in this paper are those of the authors and do not reflect the official policy or position of United States Forces Korea, the United States Army, the Department of State, the Department of Defense or the United States Government.

Disclosure: This work was supported, in part, by a grant from the US Army Research Office (grant \# W911NF1910055).

The authors gratefully acknowledge the support and assistance of the 2nd Infantry Division C5 and ORSA Planning Staff in the development of this paper. Their consideration and insight was instrumental in framing and focusing the model to ensure its relevance. A NC State colleague Osman Ozaltin provided useful suggestions that greatly enhanced the presentation of technical details. This paper also benefited from constructive comments from the editor and two reviewers that improved both the content and presentation.

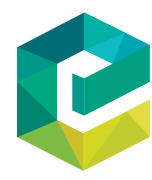

Journal of Defense Analytics and Logistics

Vol 4 No.1, 2020 No. 1,2020

Emerald Publishing Limited 2399-6439 DOI 10.1108/JDAL-05-2019-0010 


\section{JDAL 4,1}

\section{Introduction}

\subsection{Noncombatant evacuation operations definition and historical context}

Noncombatant Evacuation Operations (NEOs) are operations in which US citizens, Department of Defense (DoD) civilians and pre-designated host nation $(\mathrm{HN})$ or third-country nationals (TCN) are transported from within a foreign nation to a separate safe haven (Joint Doctrine Group, 2010, JP 3-68). These operations generally occur as a result of military conflict, political unrest or natural disaster, but they can be directed for any number of other reasons by the Department of State (DOS). The manner in which NEOs are conducted can have far-reaching positive or negative effects across diplomatic, humanitarian, military and economic realms, and they require deliberate and thoughtful planning to execute well (Junkins, 2012).

These missions are ultimately the responsibility of the DOS to order and coordinate, but it is the responsibility of military forces - specifically Geographic Combatant Commands (GCC) - "to prepare and maintain plans for the protection and evacuation of US noncombatants abroad for whom the DoD is responsible" (Joint Doctrine Group, 2010, JP 368). There are six GCCs chartered with this broad mission and generally the GCCs assign country specific NEO missions to an individual military component commander (Army, Navy, Marines or Air Force) or they choose to establish a Joint Task Force to conduct the operations.

Historically, the US has conducted over 30 NEO missions dating back to Operation Frequent Wind in Vietnam in 1975. Frequent Wind evacuated approximately 7,000 people from Saigon and southern Vietnam to US Navy vessels located in the South China Sea (Washington, 2015). This mission was successful in that it evacuated a large number of people, but the uncoordinated efforts of US military aircraft, Vietnamese Air Force and US Government (USG) supported fixed-wing assets resulted in a substantial loss of resources. Due to a lack of fuel and deck space aboard the US Navy ships, many aircraft were landed at sea or pushed overboard to make room for additional arriving aircraft. It was this disorder that provided the impetus for much of the doctrine we see at work in recent missions, such as Operation Silver Wake in Albania in 1997 depicted in Figure 1. In this mission, the DOS called for the evacuation of US Embassy personnel following the economic collapse and subsequent rioting in the capital city of Tirana. The US Navy's 6th Fleet inserted a company of Marines into the US Embassy and adjacent housing compound to provide establish security and subsequently evacuate approximately 900 personnel out to ships located in the Adriatic Sea (Germain, 1997).

This mission is representative of much of the NEO scenarios that dominate the doctrine in which the populations to be evacuated are less than 1,000 people, the operation itself is a point-to-point transportation by military aircraft, and there is a non-peer military threat opposing the mission. This is simply not the case in a South Korean noncombatant evacuation scenario.

\subsection{South Korea characteristics}

South Korea presents a number of challenges for an evacuation beyond the base scenarios covered in the doctrine. First, the scale is drastically different. Typically, less than 1,000 people are evacuated in the course of a NEO, and South Korea has over 150,000 American citizens and DoD personnel that would require transportation out of the country (United States Department of State, 2018, Seoul Annual F-77 Report). Additionally, the base scenarios present a centralized evacuation population, where in South Korea that population is widely distributed across the country. Second, that number of personnel exceeds the reasonable capacity of military aircraft available for evacuation and therefore the 


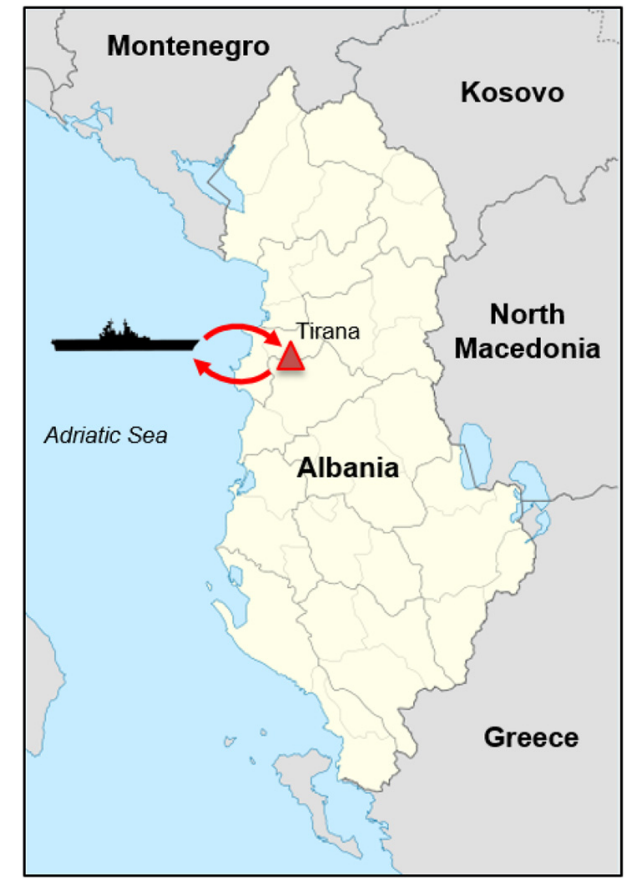

Modeling and transportation planning

Figure 1. Operation Silver Wake, Albania 1997 Point-to-point evacuation from US Embassy in Tirana to US Navy ships in Adriatic Sea

evacuation plans rely on the public transportation system of South Korea. That aspect of the plan makes good use of a powerful asset, but it results in a plan that is difficult to rehearse and refine outside of an actual evacuation. It also inserts a network component into the evacuation, where generally NEOs have been point to point from an embassy to safe haven.

Third, given the nature of the political landscape and the provocation and escalation policies employed by North Korea, the threat of large scale military action by units on the peninsula is real, and that creates a scarcity in terms of the available DoD forces to facilitate the NEO. In the majority of the evacuation missions conducted over the past 40 years that has not truly been the case. The evacuation location conflicts did not possess peer or nearpeer level militaries that would occupy the attention of the forces conducting the NEO. Given the nature of the operational environment in Korea, a noncombatant evacuation requires a dramatically different approach than those pursued in the past. Figure 2 illustrates the complexities of the South Korean NEO mission. There are many assembly points (APs) that service a distributed population, the evacuation network comprises numerous routes and modes of transportation, and there is a nearby credible threat in North Korea prepared to disrupt evacuation operations.

\subsection{Framing the noncombatant evacuation operations problem for 2 nd infantry division}

While the significance of the NEO mission is considerable, it is important to note that it is almost never the primary mission of the various military component commands - rather it is an additional responsibility contingent on political or environmental circumstances. And therefore, the military component commands develop broadly scoped and flexible plans 


\section{JDAL 4,1}

Figure 2.

The South Korea NEO mission starkly contrasts with the typical NEO scenario described in Figure 1

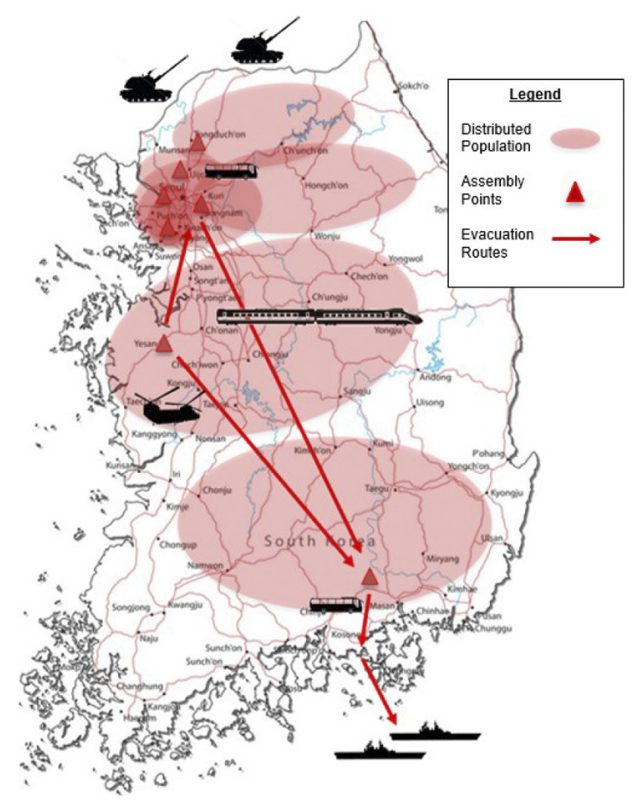

Notes: There are many assembly points (APs) that service a distributed population, the evacuation network is comprised of numerous routes and modes of transportation, and there is a nearby credible threat in North Korea prepared to disrupt evacuation operations

with the understanding that they will have to adjust based on what actually occurs on the ground. In the case of South Korea, the 2nd Infantry Division (2ID) is the military unit responsible for planning and executing a NEO on the peninsula.

In the event the DOS directs an evacuation, 2ID and subordinate units would elevate their readiness posture and move to occupy APs and key nodes of interest across the country. The population to be evacuated would then be notified and directed to report to the APs for in-processing and transportation. The military elements managing APs would report the number of evacuees present at their location to the 2ID operations center and then an ad hoc dispatching of assets would take place to move personnel on designated routes out of the country. This general process would continue until the total population to be evacuated has passed through the system.

Further investigation into the planning methodology at work in this concept of the operation re- emphasizes the challenges at play in South Korea. It is apparent that the network component and scale of this scenario is problematic for the NEO planners and this complexity has made it difficult for them to devise a comprehensive and logical approach. Additionally, the presence of a significant North Korean threat occupies much of the 2ID planners' attention, leaving portions of the evacuation operation unexplored. Specifically, no rigorous analysis or modeling of the network has been done to identify critical arcs, the modeling of evacuees arriving into the system is incomplete, and the allocation of assets to 
deal with the evacuees is reactive and not precisely motivated. This troubling lack of analysis leaves.

2ID not only without a clear understanding of the time or resources required to complete an evacuation, but without any real idea of how to shape and manage the operation given what actually is available.

The rest of the paper is organized as follows: Section 2 presents the overall objectives of the work and leading assumptions that frame the problem, Section 3 highlights existing work in the field, Section 4 outlines the specific approach and methodology applied to solve

Modeling and transportation planning the problem, Section 5 demonstrates the usefulness of the work in the form of a case study, and Section 6 makes final recommendations for application of this procedure in Korea and discusses of the novelty of this approach for similar problems.

\section{Objectives and assumptions}

The overall objective of this work is to better prepare the 2ID Commander and Staff in their planning, preparation and execution of noncombatant operations. That requires addressing the current planning deficiencies and making the full problem more accessible and manageable for those involved. That begins with modeling and analyzing the specific physical transportation network in play during an evacuation and then establishing a reasonable estimate of how evacuees will enter that system. Then the best and most feasible manner in which people can be evacuated, given limited resources, can be determined and those limited resources can be allocated in such a way as to deliberately achieve that best possible evacuation.

With the general approach determined, there are some leading assumptions that need to be introduced to make it practical and reasonable to pursue. Foundationally, NEO is a single task within a large mission set for 2ID, and it must be conducted in conjunction with other responsibilities. Therefore, any methodology needs to be flexible or be able to be easily adjusted to account for other requirements or changing circumstances. Next, the number of evacuees will always exceed the capacity of the transportation fleet and so each asset will be used multiple times through the course of a NEO. Additionally, noncombatants are expected to arrive at multiple pre-determined locations across the country, and they are expected to do so at variable rates. Finally, there exists a centrally controlled transportation fleet that can be employed to execute a NEO which we limit to buses, helicopters, and trains. We do not consider fixed-wing assets based on communications with 2ID but this is not a limiting assumption based on the model structure. This collection of initial assumptions provides context for the approach and better defines the problem itself.

\section{Literature review}

With the objectives of this problem established, it is instructive to review the procedures and solutions to similar or related scenarios that could potentially be applied in this case.

\subsection{Noncombatant evacuations}

The majority of the historic noncombatant operations do not inherently lend themselves to mathematical modeling as the missions generally involved evacuating from a single location to a separate safe haven. It is also apparent that the allocation of assets and any network analysis was done on a purely practical basis during the mission planning processes. As a result of those factors, past NEO missions do not provide significant insight into the South Korea scenario.

While these historical examples have not proven to be particularly relevant in this instance, meaningful work has been done using multi-agent models to facilitate future 


\section{JDAL 4,1}

noncombatant evacuation operations. Multi-agent models have been applied to potential evacuation operations to quickly organize available data concerning population locations, transportation assets, condition of infrastructure, fuel supplies and other factors, and then apply a series of hierarchically sorted tasks to determine how to best conduct an evacuation (Dix et al., 2002). These models make significant improvements over their control simulations but would have to be heavily modified to account for the complexity of the South Korea evacuation network. More generally, multi-agent models have also been applied to smaller scale evacuations of buildings and urban areas using behavior-related models of individual evacuees and properties of the physical environment (Karbovskii et al., 2015). The scope of this multi-agent application is a bit too narrow, as the interest of this paper is primarily on the performance of a large transportation network and the allocation of assets rather than attempting to smooth the behavior of individual actors within a system. In total, the multi-agent work has shown promise, but in the South Korea scenario, there are operational requirements that allow for a more directed approach.

The most relevant literature focuses on assisting military NEO Planners and consistently employs discrete event simulation (DES) (Kuchell, 2013; Scheer, 2011; Olsen, 2011; Gregg, 2010; Sumner and Zahn, 1996). These studies comment on the difficulty of getting accurate arrival and process data, making validation difficult; none of them are designed for use during the operation using situation reports as an operation unfolds. Kuchell (2013) presents a DES framework with modules representing various NEO network components and processes with support from an unnamed mixed-integer program to make asset routing decisions. Other NEO studies are Europe-specific and also rely on discrete event simulation (Scheer, 2011). The authors study a small NEO with two different fixed wing platforms and two different rotary wing assets. They report the total person-days for the evacuation to assist determining resource requirement in the network (food, water, etc.).

\subsection{Civilian and military medical evacuation models}

Emergency medical evacuations conducted by military and civilian organizations represent a closely related field of research to noncombatant evacuations. Significant investigation into emergency medical services concerning military aeromedical evacuation (MEDEVAC) and ambulance coverage and their associated response times has been done, and there are some practical similarities that address some of the issues present in a South Korean NEO.

Numerous military emergency medical evacuation models have been developed to resource and dispatch aerial and ground MEDEVAC assets in such a way as to provide the best possible service times for units in active combat zones. Investigation in the number and location of military treatment facilities and the density of military aircraft across a theater of operations responds to the set covering aspects of this problem (Fulton et al., 2010), while Robbins et al. (2018) apply a Markov decision process model and approximate dynamic programming to optimize the dispatching of assets. Similarly, civilian emergency medical evacuation models generally classify into those that address the staging locations of emergency vehicles, those that reallocate vehicles by either multi-period mixed integer linear or dynamically programming when demand is exceeded, or those that are principally concerned with dispatching and routing vehicles as medical emergencies are reported (Aringhieri et al., 2017). Most relevant to this scenario are models that are concerned with the reallocation of emergency vehicles in real-time in response to demand. Bertsimas and $\mathrm{Ng}$ (2019) use a two-staged stochastic and robust planning model to tactically deploy ambulances in a manner that is resistant to short term uncertainties in demand. This approach yields high-quality solutions for the emergency medical service, but the model is motivated to limit the number of slow response times while working to limit the repositioning of assets. To summarize, both military and 
civilian emergency, evacuation models provide insight into how to assess the South Korea scenario while being motivated by a different end. The aim of the NEO is to empty the system as quickly as possible, while the medical evacuations look to provide the most prompt service to individual demand points.

Modeling and transportation planning

\subsection{General evacuation models}

A number of studies use network flow approaches to plan evacuations of buildings (Kawsar et al., 2019; Park, 2015; Kisko and Francis, 1985) or cities (Yamada, 1996) without a timestaged expansion. Other studies use network flows with time-expanded networks for buildings (Shin et al., 2019; Choi et al., 1988; Chalmet et al., 1982) or cities (Lim et al., 2012) to accommodate more realistic features (Dhamala, 2014; Lim et al., 2012). Jarvis and Ratliff (1982) demonstrate the equivalency between three objectives for a time-expanded network flow as will be discussed below. While effectively minimize the total evacuation time, Lim et al. (2012) maximize the number of total evacuees for a short notice evacuation window and Shin et al. (2019) introduce multiple options for the objective function. For a recent survey of time-expanded network flow models, refer Dhamala (2014).

For sufficiently large problems with computational runtime issues, recent studies have also explored heuristics and inexact algorithms that use Dijkstra's algorithm to identify evacuation paths feeding a constructive approach that maximizes and schedules the flow on each path (Shin et al., 2019; Lim et al., 2012). Lu et al. (2005, 2003) implement a generalized shortest path search algorithm for transportation networks and compare performance with time-expanded network approaches that use linear programming. Saadatseresht et al. (2009) use a multiobjective evolutionary algorithm for evacuation planning and demonstrates a geographical information system (GIS) integrated approach for an evacuation scenario of 22,000 people from a 371 acre area to 7 safe zones. Others, such as Gan et al. (2016), integrate optimization with traffic simulation for a hybrid approach.

While specific work on noncombatant evacuations appears limited, the broader category of evacuations related to natural disasters shows significantly more breadth and depth of investigation. Most existing studies recommend implementing contraflows or lane reversals in various critical areas of the networks to smooth outflow and reduce congestion and wait times (Praveen et al., 2010). Other models seek to optimize the total performance of the system by building objective functions based on the average vehicle speeds across the network. These produce solutions that recommend metering the traffic flow onto key thoroughfares to keep network accumulation below a critical level to achieve the best system performance (Zhang et al., 2015). These methods themselves are not cleanly applicable to South Korea, largely due to the fact that the models rely on the assumption that the population to be evacuated is itself mobile. That is not the case in South Korea, where less than 43 per cent of the population has access to a personal vehicle (Sung-jin, 2016) and that number drops significantly in urban areas, where the population to be evacuated is based. These issues point to another aspect of evacuation models - specifically those that use the public transportation system. The interested reader may consult the most recent surveys on general evacuation and disaster operations management (Galindo and Batta, 2013; Altay and Green, 2006; Hamacher and Tjandra, 2002). See also the homeland securitythemed survey by Wright et al. (2006).

\subsection{Disaster evacuation models using public transportation systems}

Related studies optimizing evacuation roadway traffic address the approximate scale of the problem - such as the evacuation Knoxville and Knox County, TN, requiring 157,733 vehicle trips (Yuan et al., 2006; Yuan, 2005) - yet the most pertinent and promising studies to this 


\section{JDAL 4,1}

paper concern the construction of models that use the public transportation system to assist in an evacuation. While the motivation for the evacuation differs from that of NEOs, the approximate scale and network considerations closely relate to a scenario based in South Korea.

A number of significant storms damaging urban areas in the early 2000s revealed the need for investigation into the use of public transportation assets to evacuate the car-less population. Early studies applied mixed-integer linear programming (Sayyady and Eksioglu, 2010) to use the local bus fleet to minimize the total evacuation time, assuming single trips and known pickup locations. Bish (2011) introduces a model explicitly for busbased regional evacuations. Other models capture the demand uncertainty based on arrivals into the system (Lakshay and Bolia, 2019; Song and Yan, 2016; Goerigk and Grün, 2014; Abdelgawad et al., 2010) and some use a vehicle routing procedures to recommend bus routes to minimize total evacuation times. Many are based on known pickup and drop off locations of the buses and were later extended by Kulshrestha et al. (2014) to select optimal pickup locations for evacuees to assemble prior to transportation. Goerigk et al. (2015) and Goerigk and Grün (2014) apply a robustness approach to a bus evacuation but do not consider alternate transportation modes as the study focuses on the evacuation in the city of Kaiserslautern (Germany).

While there are some specific nuances that would need to be considered in the case of a South Korea evacuation, the framework established in these previous studies describes a practical approach to the problem. Aspects of an evacuation model, constructed for use by the 2ID, that differ from previous works would need to capture the three distinct modes of transportation: bus, rail and helicopter. Because it is intended to be a practical tool, it would need to adopt a multi-period approach so it could refine its recommendations based on actual arrivals into the system as well as fluctuating bus, train and helicopter fleet sizes. It would need to account for capacitated nodes at certain reception or intermittent staging nodes, and it would need to consider the costs of operating evacuee intake points on the system. A mixed integer linear program that integrates those facets, along with the existing works use of demand uncertainty, defined intake locations and the general minimization of total evacuation time would yield a tool that recommends optimal employment of limited assets to achieve an evacuation in South Korea.

\section{Methodology}

Aspects of the South Korea evacuation scenario coupled with the specified objectives of 2ID naturally point toward the application of a minimum cost network model to optimize the flow of evacuees through the transportation network. That requires the network structure itself as well as a model for how evacuees will arrive into the system. Those two pieces can then be used within a mixed integer linear program to determine the optimal configuration of evacuee flow that minimizes the total time of the NEO while considering the limited assets available. After post-processing, that solution can be used within a vehicle routing procedure to produce a route schedule for each individual asset to facilitate the complete evacuation. This methodology effectively addresses problems with the existing plans and gives 2ID mission performance statistics and an actual executable schedule for their assets to make the complete NEO possible. Figure 3 illustrates the approach.

\subsection{Network modeling}

Beginning with the evacuation network it is useful to develop a basic understanding of the sequence of events and the flow of personnel within an evacuation so that the model and its features can be clearly communicated. First, the most typical scenario for an evacuee 


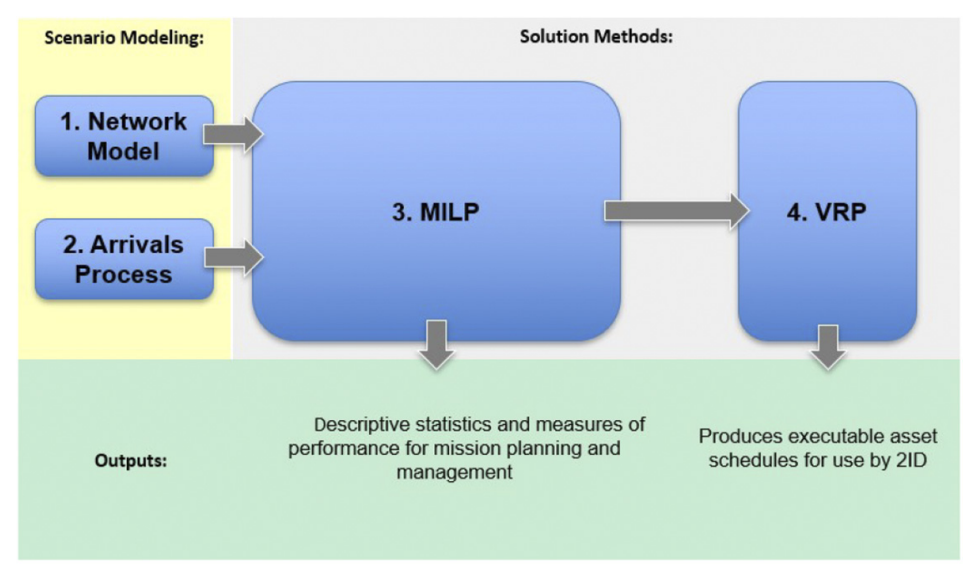

Modeling and transportation planning

Notes: The first step in the procedure is to form the structure of the network using known node locations and the viable routes between nodes. The arrival process then models flow into the network at key nodes based on population data. Those two aspects form the basis of the MILP, the objective of which is to minimize the total evacuation time. The MILP produces descriptive statistics and information that assists in mission planning and force management. The MILP solution is post processed into a vehicle routing procedure that provides a route sequence for each asset that facilitates the full evacuation

Figure 3.

General solution procedure and outputs

following their arrival to an AP would occur as follows: bus movement to a US military controlled train station, train movement south to a station located near the relocation center, bus movement to the relocation center, and then another bus movement to the Air/Sea Port of Debarkation (A/SPOD) as assets become available to move them off peninsula. Numerous other alternatives exist: an evacuee could be bused from the AP directly to the port or they could be flown by helicopter from the AP to a more advantageous position south for rail transit.

4.1.1 Structure. The components of that sequence critical to the actual modeling process are the APs, relocation center, and A/SPOD locations. These form the nodes of the network and the movement alternatives between them build out the actual structure of the network. APs are located on established military installations, the relocation center is located in the vicinity of Busan, and the port of Busan serves as the primary SPOD. Figure 4 depicts approximate geographic node locations and those points are each generally connected via bus, train and helicopter arcs. There are a few exceptions related to where the trains can physically travel, or where helicopters are permitted to land, but in most cases, all nodes connect to all other nodes. This collection of nodes and their associated connections form the basis for the network structure.

4.1.2 Time-staged expansion. Recall the leading assumptions that the number of evacuees exceeds the fleet capacity and the notion that people will arrive into the system at different locations at irregular intervals. These two assumptions lead to performing a timestaged expansion of the network structure to adequately capture the behavior of the system.

To facilitate that expansion, it is necessary to first determine the travel times for all of the bus, train, and helicopter arcs. This is achieved through the use of web-based navigation 


\section{JDAL 4,1}

Figure 4.

(color online)

Network structure of

South Korea

evacuation

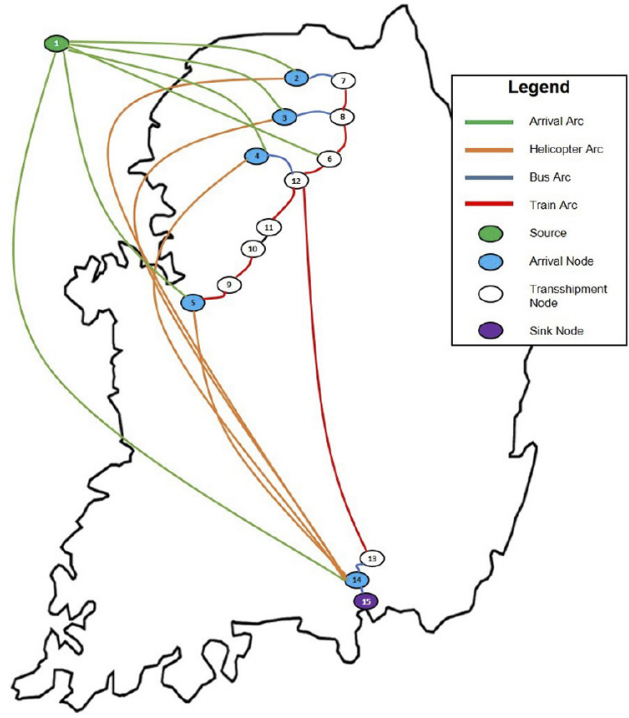

Notes: For comparative reference, South Korea is slightly larger than Indiana by area (CIA 2019b). The interested reader may consult CIA (2019a) for the transportation network details of South Korea. Full network details available from (Kearby, 2019, p. 11, 63)

and mapping sites (Waze, 2018), published train schedules (KTX, 2018) and direct calculation in the case of helicopter arcs considering aircraft cruising speeds. In addition to the arcs that physically transport evacuees, as a result of the time-staged construction there are also arcs that carry flow across time periods while remaining at the same node. The collection of these node-arc travel times is used to construct an incidence matrix for use in the optimization model. In this configuration it is convenient to include a source and sink node to easily capture and motivate all flow into and out of the system. The complete results of the expansion yield a concise network for use by the model.

\subsection{Arrivals process}

Currently, evacuees are expected to arrive into the system at several different locations spread across the country at an unknown rate. Due to the scale and political implications of an evacuation on the peninsula, there is a lack of empirical data from 2ID to describe this process and so modeling it becomes a necessity. 2ID provided the $2018 \mathrm{~F}-77$ Report of Potential Evacuees (United States Department of State, 2018) which is essentially a census of the size and distribution of the population to be evacuated. Further, Kuchell (2013) reports that DOS claims most arrivals are bell-shaped but positively skewed. The interested reader should also consult Murray-Tuite and Wolshon (2013) for a thorough review of evacuation demand modeling considerations, though we lacked sufficient data to incorporate them here. Using the F-77 data and the assumption that people will be evacuated through the nearest $\mathrm{AP}$, this paper directly calculates the number of people who are expected to be evacuated 
through each node. That forms the basis of the model, and then through the use of the Poisson distribution and a mean arrival rate parameter, the number of evacuees who arrive at each location in each specific time period can be determined. It is reasonable to assume that arrivals follow a Poisson distribution because the behavior and arrival time of widely distributed individual evacuees to APs are unrelated to one another and independent. The following summarizes the modeling of the arrival process:

$$
q_{i t}=P_{i t}\{W=w\} \cdot \text { population }_{i}
$$

where

$$
\begin{aligned}
& q_{i t} \quad=\text { Number of evacuees arriving at node } i \text { at time period } t \\
& \text { population }_{i}=\text { Total evacuees assigned to assemble at node } i \text {; } \\
& P_{i t}\{W=w\}=\frac{\left(\lambda_{i} z\right) w_{e}-\lambda_{i} z}{w !}=\text { Probability of complete evacuation of node } i \text { at time period } t \text {, } \\
& \lambda_{i} \quad w ! \quad=\text { Average time for completion of all arrivals into node } i \text {, } \\
& z \quad=\text { Segment of interest, equal to } 1 \text {; and } \\
& w \quad=\text { Time for completion of all arrivals into node } i \text {. }
\end{aligned}
$$

Modeling and transportation planning

This permits the unit getting location-specific arrival profiles, such as populations closer to the demilitarized zone evacuating faster than those to the south, while only requiring a single parameter to estimate. This is important given the lack of data. However, the arrivals process is modular in that a more sophisticated arrival model need only output $q_{i t}$ in the end to be compatible with the remainder of this paper.

\subsection{Model}

This section presents a mixed-integer linear program with the objective of minimizing the total number of people-minutes of an evacuation. The following outlines introduces the notation, formulates the model and discusses the model.

Sets

$N \quad=$ Set of Unique Node Locations;

$N_{A} \subset N=$ Set of Assembly Points; and

$K=\{0,1,2,3\}$ for $\{$ source, bus, train, helicopter $\}=$ Set of Transportation Modes.

Index Use

$i, j \in N=$ Indices for Node Locations;

$s \in N$ = Super Source Node;

$d \in N=$ Sink Node

$t \quad=\{1,2,3, \ldots, T\}=$ Number of 30 minute allocation cycles (or time periods), over the full evacuation time horizon; and

$k \in K=$ Index for Transportation Mode.

Given Data

population $_{i}=$ Total number of personnel to be evacuated by assembly node $i \in N_{A}$;

$q_{i t} \quad=$ Planned personnel arriving at node $i$ in time period $t$

$c_{i j}^{(k)} \quad=$ Cost penalizing outflow directly related to the time period in which flow occurs;

$A^{(k)} \quad=$ Network incidence matrix describing network structure for mode $k$; and

$p_{i j}^{(k)} \quad=$ Transit time (in time periods) from node $i$ to node $j$ using mode $k$.

\section{Parameters}

$L^{(k)}=$ Minimum number of evacuees to use a single asset for mode $k$; and

$U^{(k)}=$ Total fleet capacity for mode $k$ in number of evacuees. 


\section{JDAL}

4,1

\section{Decision Variables}

$x_{i j}^{(k)}=$ Evacuee flow from node $i$ to node $j$ using mode $k$ in time period $t$; and

$y_{i j}^{(k)}=$ Indicator for Evacuee flow from node $i$ to node $j$ using mode $k$ in time period $t$

$$
\begin{gathered}
\min _{x} \sum_{i j k t} c_{i j t}^{(k)} x_{i j}^{(k)}(t) \\
x_{s, j}^{(0)} \in N_{A}(t)=q_{j t} \quad \forall j, t \\
\sum_{i k t} x_{i, d}^{(k)}(t)=\sum_{j t} q_{j t} \\
\sum_{i \mid i, j \in A^{(k)}} x_{i j}^{(k)}(t)-\sum_{i \mid i, j \in A^{(k)}} x_{j i}^{(k)}\left(t+p_{j i}^{(k)}\right)=0 \quad \forall j, k, t \\
x_{i j}^{(k)}(t) \leq U^{(k)} y_{i j}^{(k)}(t) \quad \forall k,(i, j) \in A^{(k)}, t \\
x_{i j}^{(k)}(t) \geq L^{(k)} y_{i j}^{(k)}(t) \quad \forall k,(i, j) \in A^{(k)}, t=1, \ldots, \lambda_{i} \\
\sum_{\tau=\left(t-p_{i j}^{(k)}\right)^{+}}^{t} x_{i j}^{(k)}(\tau) \leq U^{(k)} \\
\quad \forall k,(i, j) \in A^{(k)}, t \\
x_{i j}^{(k)}(t) \geq 0 \text { and Integer } \\
y_{i j}^{(k)}(t) \text { Binary }
\end{gathered}
$$

The objective (2) seeks to minimize the total time of an evacuation through the allocation to transportation assets across decision cycles. It accomplishes this by establishing a cost for exiting the network in each period, with the cost increasing according to the period in which the exit occurs. In the results presented below, $c_{i j t}^{(k)}=t$, which is simultaneously equivalent to minimizing the average time for an evacuee or maximizing the evacuation output in the first $n$ time periods for $n \leq \bar{T}$, where $\bar{T}$ is the minimized time to evacuate the network achieved by (2) (Jarvis and Ratliff, 1982). In general, $c_{i j t}^{(k)}=t$ should be a non-decreasing function in t. Node and arc-level network details are available in Kearby (2019, p. 11,63).

Constraint (3) ensures evacuees arrive to the assembly points in the right time periods. This is designed to be modular to permit testing different assumptions which result in different $q_{i t}$. Constraint (4) requires all evacuees to be evacuated to the super-sink node. The 
evacuee flow balance constraint is (5) where the notation $i \mid i, j A^{(k)}$ means for $i$ given that there exists a feasible (non-zero) $\operatorname{arc}(i, j) A^{(k)}$ for transportation mode $k$. This is equivalent to

$$
\sum_{i} a_{i j}^{(k)} x_{i j}^{(k)}(t)-\sum_{i} a_{j i}^{(k)} x_{j i}^{(k)}\left(t+p_{j i}^{(k)}\right)=0 \quad \forall j, k, t
$$

Constraints (6) and (7) work together to provide an upper and lower bound on flows across a singular arc within an individual period. Constraint (6) defines the fleetwide capacities for each transportation mode. We assume capacities are 45 (people) for buses, 750 for trains, and 35 for helicopters. For example, if there are five helicopters available, $U^{(\text {helo) }}=5 \times 35=175$. To incorporate senior leader planning guidance and prevent unnecessarily planning to use an asset for one person, minimum asset utilization thresholds, the $L^{(k)}$, are 30 (people) for buses, 100 for trains, and 10 for helicopters. Note that (7) is only active until the arrival process reaches $\lambda_{i}$; where $\lambda_{i}$ is the mean arrival completion time parameter applied to each node. This prevents committing assets early on for one or two evacuees and is unnecessary once sufficient numbers of evacuees arrive. For later time periods, such trips may be required to evacuate remaining people (maintains feasibility). If $\lambda_{i}$ is non-integer, we suggest letting using $\left[\lambda_{i}\right]$ in (7).

Constraint (8) is a multi-period fleet capacity constraint that effects flows across time periods and accounts for evacuation flows already underway. It ensures that for all allocations of the fleet, the assets in use never exceeds the total fleet capacity in any one time period. To illustrate how this constraint functions, reference Figure 5. In that example, if scheduling flow when $t=2$, the flow originating from Node 2 when $t=1$ must be considered since that arc, and its capacity, is still underway during the scheduling time period. In the actual formulation, this constraint is active across bus, train, and helicopter arc groupings and working to provide a tighter bound on the capacity. The notation $(z)^{+} \equiv \max (z, 0)$.

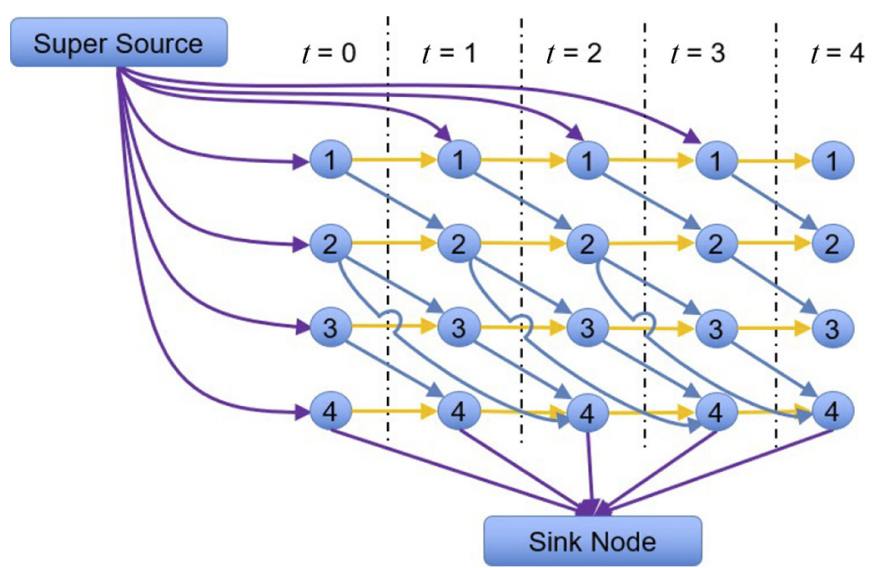

Notes: Physical flow between different nodes, as well as carried flow between the same node, occur across time periods. All flow into the system originates at the Super Source and can be directed toward any node, within any time period. Similarly, all flow leaving the network is captured in the Sink Node

Modeling and transportation planning

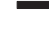




\section{JDAL 4,1}

Finally, constraints (9-10) enforce non-negativity and the appropriate discrete values. Note that as written, the model is a integer (linear) program. However, given integer population and transportation capacity data, the integer requirement on $x_{i j}^{(k)}(t)$ in $(9)$ is unnecessary. For any feasible, $y_{i j}^{(k)}(t) \in\{0,1\}$ the remaining constraint matrix in $x_{i j}^{(k)}(t)$ remains total unimodular (Wolsey, 1998; Chen et al., 2010).

Thus keeping the binary requirement in (10) but relaxing the integer requirement (9) on $x_{i j}^{(k)}(t)$ for the full $156 \mathrm{k}$ evacuation population reduces the solution time from $6 \mathrm{~min}$ to $20 \mathrm{~s}$ (with 0.1 per cent optimality gap) and converts the model into a mixed integer linear program (MILP). The solution to this formulation determines the optimal flow configuration of personnel to minimize the required time of an evacuation.

\subsection{Vehicle routing procedure}

The solution to the time-staged network model linear program is a single vector that details the time instance specific flow of every arc across the full time horizon. The position of an individual flow within this vector indicates the quantity of people moving as well as the period it is scheduled to occur. The location within the vector also describes the transportation mode responsible for executing a particular movement and knowing the capacity of each asset type, the number of assets required is directly calculated. Redefining the optimal flows as the number of full asset shipments necessary, each with defined start times, readies the model solution for the application of a vehicle routing procedure. To complete the formulation, constraints are applied to each transportation type to limit their capacities to a single shipment, and assign a depot to initiate and end route sequences.

A vehicle routing strategy is used using a savings route construction procedure followed by two-opt improvement. The savings procedure follows the Clarke-Wright heuristic that calculates the savings associated with merging shipment pairs as opposed to conducting them independently (Vigo and Toth, 2014). Routes are then constructed based on minimizing the total cost of completing all shipments. In this instance, cost is equivalent to time, and as such the procedure uses the time-staged network flow travel times to motivate the heuristic. Once the routes are constructed, two-opt improvement performs an exhaustive series of edge exchanges to ensure the optimum collection of route sequences. The complete solution to the vehicle routing procedure is a time specific location sequence for each asset available to $2 \mathrm{ID}$.

The vehicle routing procedure solution preserves the constraints built into the model. Since the shipments and associated time constraints are they themselves governed by fleet size and total capacity, the routing procedure effectively carries those boundaries forward into the route construction. This represents a novel approach, in that it indirectly constrains the number of routes the Clarke-Wright savings procedure will construct.

\subsection{Output summary}

Following this solution methodology ultimately produces significant results for two major aspects of this problem. First, model results provide 2ID with performance statistics that describe the actual evacuation operation. Total evacuation time, rate of evacuation, wait times through the system, and closure times for APs are all easily lifted from the optimal solution. This is a tremendous improvement over the state of the existing plan where the time and resource requirements of this mission were essentially unknown. Now 2 ID can actually manage and allocate resources at the outset of a NEO to shape the operation to meet its other mission requirements. Second, this method addresses another weaknesses in the current planning, specifically the assignments of the transportation assets under 2ID control. Whereas before the strategy of purely reactive; now the routing procedure yields a 
detailed schedule for each asset that is driven by the solution to minimize evacuation time. Example reports to help manage a NEO at the tactical and operational level are provided in the Appendix.

\section{Case study}

\subsection{Base scenario and performance metrics}

The standard model outputs are useful, but the true utility of this methodology is demonstrated in the form of a case study. To illustrate this and prove its ability to aid decision makers in both planning and orchestrating a noncombatant evacuation, we present a series of experiments based on a plausible evacuation scenario. This study consists of two parts: one focused on planning the evacuation under additional mission requirements and the second revolving around responding to changes in the environment as the operation is conducted.

For the purposes of this exercise, the base scenario to be investigated will evacuate 156,545 noncombatants with a fleet of $12 \mathrm{CH}-47$ Helicopters, 100 passenger buses, 24 trains and will consider an arrival rate that corresponds to an average of 2.5 days to complete assembly. The logic for starting at this configuration is that it represents a middle position between likelihood of occurrence and stress placed on the system and will therefore be of the greatest value for 2ID (LTC Erickson, 2018).

This configuration results in the evacuation taking 8.6 days or $207.5 \mathrm{~h}$ to complete, the evacuation rate is 754.4 people/ $\mathrm{h}$, the average evacuee wait time in the system is $58.3 \mathrm{~h}$, and on average the AP sites close at 5.9 days. Figure 6 describes the inflow of arrivals into the system and captures their outflow and the completion of the evacuation. For clarity, these plots use a $1 \mathrm{~h}$ time step.

\subsection{Planning requirements and adjustments}

To demonstrate the value of this model as a tool for $2 \mathrm{ID}$ requires employing it under more realistic conditions. In the course of a real evacuation it is understood that $2 \mathrm{ID}$ will be

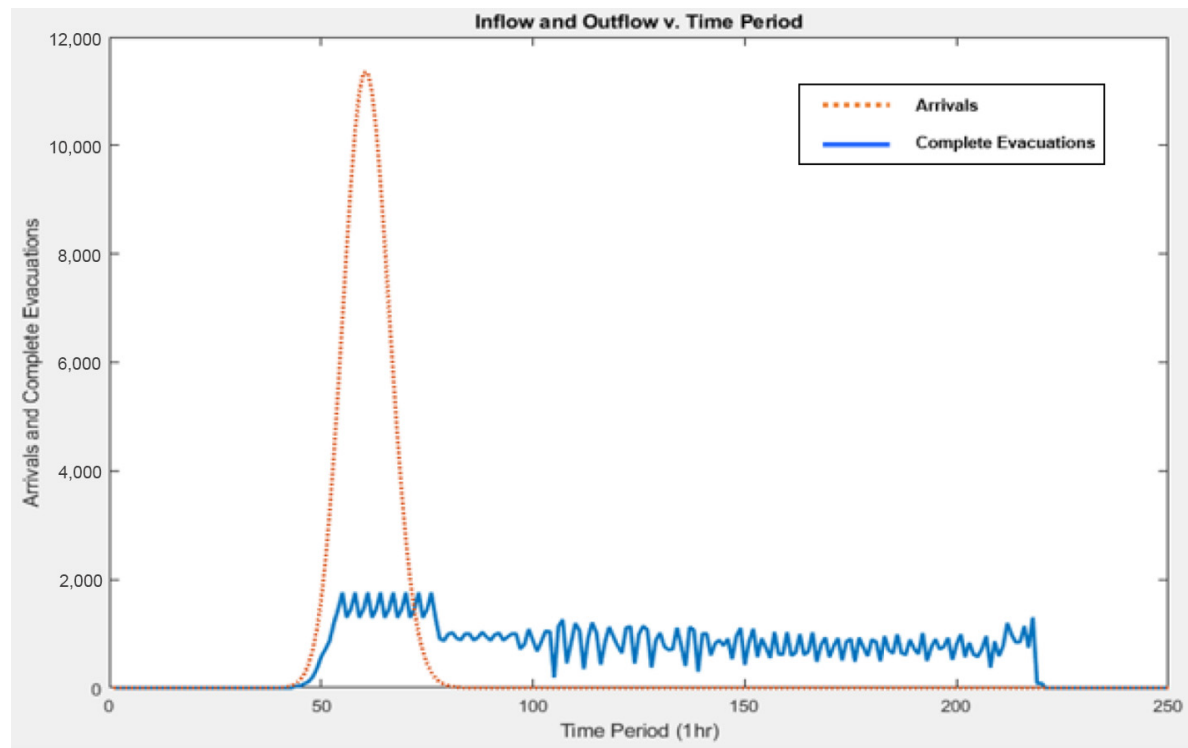

Modeling and transportation planning
Figure 6. (color online) Inflow and outflow v time period of the base scenario 
$\underset{4,1}{\mathrm{JDAL}}$

56

conducting numerous missions simultaneously and that NEO requirements will be in competition for organizational energy and resources. This study attempts to replicate an evacuation scenario that is representative of the true requirements for 2ID by building in three additional requirements.

Consider the following scenario: the deterrence efforts of the USA, South Korea and the broader international community have faltered and direct military conflict with North Korea appears imminent. The US Department of State has indicated that a NEO of all DoD Families, USG Employees and US Citizens will begin in two days. 2ID has elevated its readiness posture and is planning for forward mobilization and occupation of designated defensive battle positions in 9.5 days. 2ID scouts, who for the purposes of this case study operate AP3, are expected to establish a screen and conduct reconnaissance and surveillance missions beginning in six days. Additionally, stores of bulk rations and water are limited and can only reasonably support the population that needs to be evacuated for $24 \mathrm{~h}$.

There are three requirements in the case study:

(1) early closure of AP3;

(2) time limit for the evacuation;

(3) evacuee wait times of less than $24 \mathrm{~h}$.

Each facet of this scenario explores a different constraint, or a different way to adapt the model to meet the needs of 2ID. The first requirement focuses strictly on ending the mission before the base experimentation conditions say it can be completed. As previously mentioned, 2ID can shift focus and reposition its own resources and this iteration will meet the new mission requirements by determining just how much additional fleet capacity of each mode is required to satisfy the need. The second stipulation implies that the early closure of an AP is necessary, and this directed model adjusts the arc capacity according to the required closure time to ensure that occurs. The third requirement is aimed at limiting the waiting time of evacuees as they move through the system. Evacuees are told to assemble with food and water, but 2ID would have supporting rations available and therefore the wait time through the system needs to be less than $24 \mathrm{~h}$. This iteration of planning investigates the impact of metering arrivals into the system by making directed announcements to specific slices of the evacuation population. This case study attempts to demonstrate how early planning with the model can be refined to meet real-world operational requirements (Table 1).

5.2.1 Requirement 1. Early AP closure. The first additional requirement is the mandated closure of an AP on a particular day. It is necessary to start with this requirement as it can be achieved only by modifying the structure of the time-staged network. Once this adjustment is made, subsequent required changes will all operate within the new framework and the results will build in a cumulative manner; otherwise, they would be independent and thus less useful.

Table 1.

Case study requirements beyond the base scenario

\begin{tabular}{|c|c|c|c|c|c|c|c|c|}
\hline Issue addressed & $\begin{array}{c}\text { Arrival profile } \\
\text { (mean arrivals } \\
\text { complete at day) }\end{array}$ & Helo & Bus & Train & $\begin{array}{l}\text { Evac time } \\
\text { (hours) }\end{array}$ & $\begin{array}{l}\text { Evac time } \\
\text { (days) }\end{array}$ & $\begin{array}{l}\text { Average evacuee } \\
\text { waiting time } \\
\text { (hours) }\end{array}$ & $\begin{array}{c}\text { AP site } 3 \\
\text { closure }\end{array}$ \\
\hline $\begin{array}{l}\text { Base scenario } \\
\text { Planning }\end{array}$ & 2.5 & 12 & 100 & 24 & 207.50 & 8.65 & 58.32 & 8.96 \\
\hline requirements & - & - & - & - & 180 & 7.5 & 24 & 4 \\
\hline
\end{tabular}


Constructing an evacuation plan that ensures AP3 is closed before Day 4 is slightly more complicated than a direct parameter adjustment, but is still easily handled by the model. However, before changes to the model are made it is first necessary to ensure that whatever the desired AP closure time occurs after evacuee assembly is complete. The assembly timeline acts as a lower bound for site closures, as the operating assumption is that a site cannot be closed down while evacuees are still arriving. If that condition is met, then it is possible to achieve an early AP closure by placing an upper bound of zero on the transperiod arcs beginning on the required closure day. That modification essentially ensures

Modeling and transportation planning that all evacuees that arrive into AP3 have departed before the upper bound is applied. Once this constraint is factored into the model, the objective function will allocate assets in such a way to ensure all evacuees are clear before Day 4.

This can be seen in the allocation of assets on Day 4 as well as the summarized results of the descriptive statistics for the full schedule. Table 2 highlights the changes in the key metrics and details how the new schedule meets the additional requirements. It should be noted that this constraint slows the evacuation slightly and that further adjustment and experimentation is necessary to ensure the schedule meets the new planning requirements.

5.2.2 Requirement 2. Time limit. The second requirement to plan against is the evacuation completion suspense at NEO + 7.5 days as a result of another operation. Further experimentation with the model at the population level of interest yields information about the sensitivities to changes in certain fleet sizes. Twelve additional experimental runs were made, while varying the levels of each specific transportation mode, as opposed to the simple capacity adjustments made during earlier experimentation.

Using the results from those additional runs, a simple linear response surface model (Law, 2007) was constructed to allow for the quick and reasonably accurate calculation of evacuation times based on varying quantities of bus, helicopter and train assets. Buses (or other ground transportation assets) are the most abundant transportation asset available to 2ID, and while other asset configurations do exist, for simplicity and feasibility only buses and helicopters have been adjusted to illustrate the impact of changing capacities. Table 3 illustrates how running the model for a variety of bus and helicopter fleet sizes provides understanding of the trade-offs involved and the relative value of assets. Applying the response surface model showed that adding 31 buses will ensure that the plan meets the mission requirement of completing the evacuation in under 7.5 days, but it is necessary to check this estimated performance using the model as the relationship is not strictly linear. For example, running the model with 31 additional buses actually produces an evacuation time of $162 \mathrm{~h}$, and so it is unnecessary to add all 31 buses to meet the requirement. The values in Table 3 are results from repeated runs of the optimization model. Application of the predictive expression and simple adjustment of the parameters represent the most direct way to improve model performance, and it lends invaluable insight for advanced planning by 2ID. For more details see Kearby (2019).

5.2.3 Requirement 3. Evacuee wait times. The third new mission requirement to plan against concerns the available supply of rations for the evacuees and therefore the waiting time through the system. With a limited supply of rations available the wait time in the system needs to be less than $24 \mathrm{~h}$. Due to the fact that for much of the evacuation process the model is operating at maximum capacity, it is necessary to try and influence the arrival profile to affect wait times through the system.

The arrival process represents one of the areas of greatest uncertainty within the model, and so while it is possible to influence or direct the behavior of the evacuees, when they will actually arrive is difficult to predict with a high degree of confidence. That uncertainty is built into the arrival process during the initial formulation, but the adjustments made in this 
JDAL

4,1

58

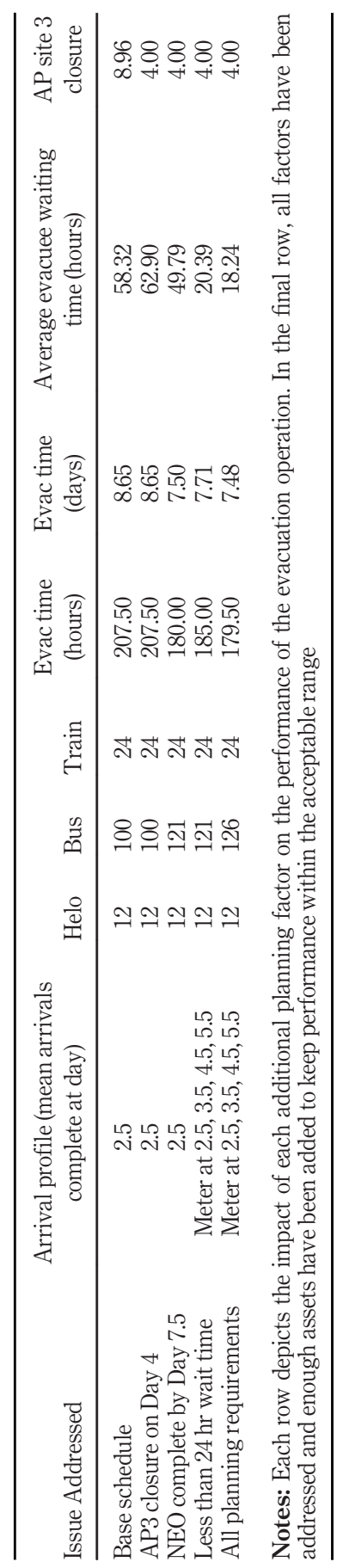

Table 2.

Progression of the planning

requirements case study 
consideration further those early arrival assumptions. The first formulation makes the assumption that the arrival process will be complete in a specified number of days based on when evacuees are notified. This new consideration advances that assumption by supposing that individual portions of the total evacuee population will behave independently according to their notification. For the smallest populations this is not unreasonable as DoD families and USG personnel have likely experienced some NEO training and can be expected to understand the implications of staggered notification and report when they are directed. But as the evacuee population expands to US Citizens or

Modeling and transportation planning TCNs, this assumption may erode and the arrival profile may become more variable. Operating as if the assumption is valid, it is possible to notify slice elements of the total population in to produce an arrival profile that could aid in reducing the evacuee wait time through the system.

With that assumption in place, the arrival profile can be modified by the number of notifications and evacuee population slices they address. Inherently, there are risks present in this option as those evacuees who are not notified to assemble may remain in a hostile area for a longer period, but this represents a working strategy to reduce waiting times. Again, to determine the required number of notifications further experimentation with the model is necessary and so the number of notifications is incrementally increased until the waiting time is reduced to below the working threshold. For example, if there are to be three notifications, one third of the evacuees will be notified on each subsequent day. This effectively meters the arrivals into the system and limits evacuee wait time. It is important to note that as the arrival profile is modified by multiple announcements, other key metrics change as well, and so any complete solution will require further adjustments.

5.2.4 Planning requirements case study result. The planning portion of this case study illustrates how the model can be employed to handle a number of different planning considerations beyond the direct evacuation mandate. Applying the changes discussed for each of the additional requirements to the model produces the schedule performance captured in the Table 2 and Figure 7.

\subsection{Disruptions and adjustments}

The next phase of this case study is focused on the execution of an evacuation and how to use the model in response to disruptions or other variable circumstances. Building on the planning scenario, three additional disruptions will be applied that the model must account

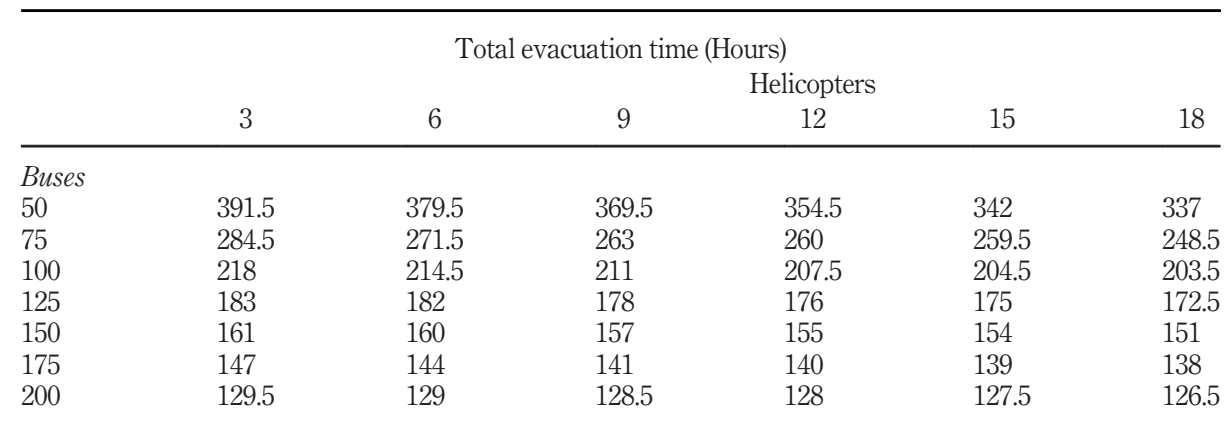

Note: Here the train fleet is held constant at 24 . All values are the results from the optimization model in section 4.3
Table 3.

Visualization of total evacuation time changes against varying bus and helicopter fleet sizes 


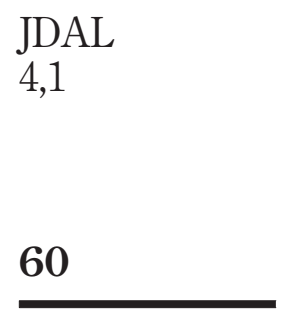

Figure 7. (color online) Inflow and outflow v. time of the solution to the planning case study

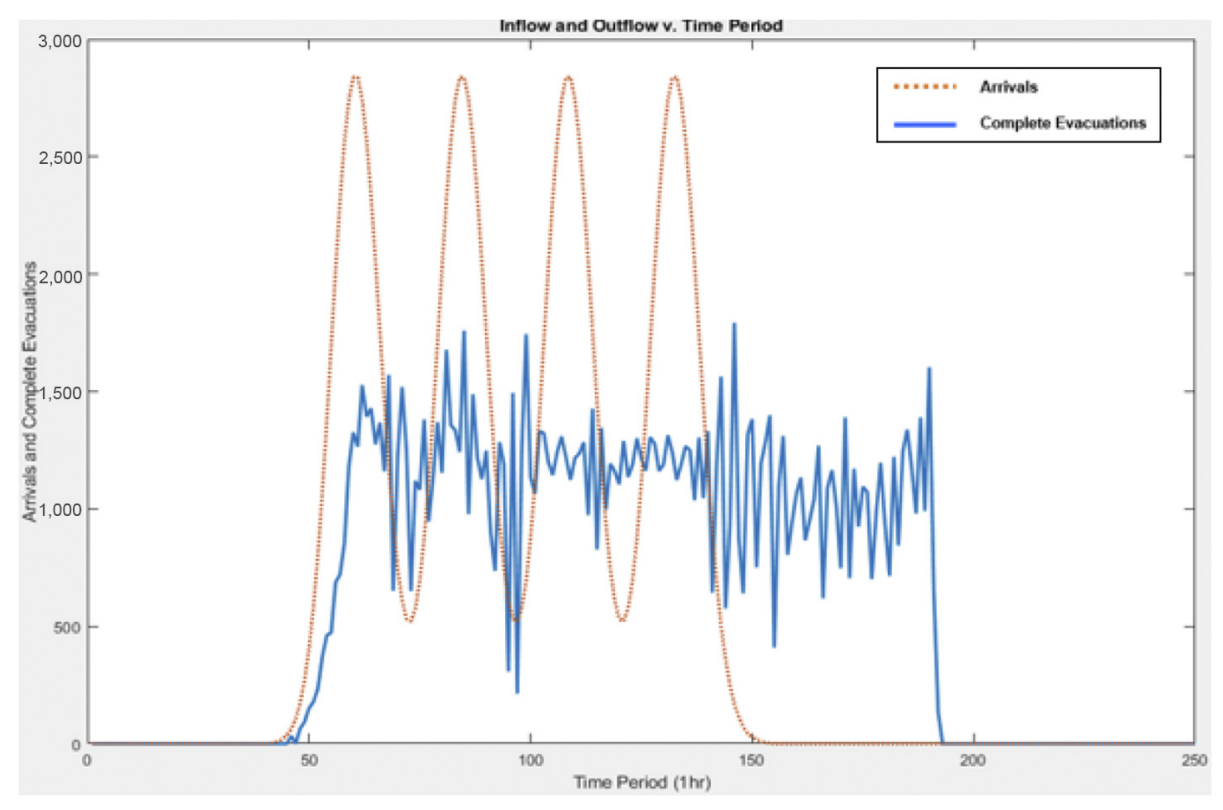

Note: Visually, the effects of changing the arrival profile are apparent in the figure and it is also clear that the operation ends before the specified time limit

for while scheduling assets. Consider the following likely events: loss of transportation assets as a result of military conflict, closure of a route or arc and the irregular arrival of evacuees to APs. In terms of the actual implementation, the model will account for the loss of eight helicopters from the fleet from Day 3 forward, the closure of all bus routes from AP1Camp Casey to Busan beginning on Day 4, and the irregular behavior of arrivals into the network.

Summarizing disruptions to the evacuation:

(1) irregular arrival of evacuees;

(2) loss of assets; and

(3) closure of evacuation routes.

5.3.1 Disruption 1. Irregular arrivals. Real time utilization of the model and transportation asset scheduler is driven by the reporting of arrivals by the units managing each AP. To this point, arrivals to APs have been approximated by the Poisson distribution detailed in Section 4.2. This adjustment marks a change how arrivals come into the system by attempting to simulate an irregular arrival distribution for the model to schedule against since actual NEO "arrival patterns can vary greatly" (Scheer, 2011; Kuchell, 2013). This is accomplished first isolating the periods in which arrivals occur and recording the corresponding arrival quantities. Those arrival quantities are then randomly assigned to the range arrival periods to create a new, and irregular distribution for the model to deal with. Depending on what requirements the model is attempting to account for, the irregular distribution could present a better or worse alternative to the incumbent Poisson 
distribution. With the new arrival distribution generated to simulate the reporting of APs, the remaining disruptions can be applied to the model to further demonstrate how the model can be used during the course of an evacuation. Figure 8 highlights the performance of model considering this irregular distribution of arrivals. Of interest, this particular irregular arrival profile erodes the performance of the schedule as it yields a slower total evacuation and longer wait times than that of the planned scenario. This will not always be the case as the arrival profile could as easily skew early as opposed to the slightly early distribution created for this model. This further reinforces the utility of running of the model and scheduling procedure repeatedly as new information is reported from the APs.

5.3.2 Disruption 2. Loss of assets. It is probable that over the course of an evacuation the size of the transportation fleet could change as a result of maintenance issues or military action. Suppose that on the third day of the planned evacuation, eight helicopters are lost to maintenance issues. The model can account for this change in capacity through the adjustment of the train constraints beginning on Day 3. Conceptually, this is fairly straightforward however due to the time-staged nature of the network it is a tedious implementation. Currently, the capacity constraints operate in three ways. Single arcs have an upper bound related to the total fleet capacity of a particular transportation mode. Transportation mode arcs are also grouped by type and are collectively assigned an upper bound according to their total fleet capacity across a number of time periods. This ensures that the capacity is not exceeded in either a single time period or a series of time periods where transportation is occurring. The third constraint only applies through the first half of the arrival process and ensures that arc flow, if scheduled, will only occur above a specified minimum occupancy level. Therefore, no trips of single digit passengers will be scheduled by the model. As a result of this formulation, adjusting the capacity of a particular transportation mode within the schedule essentially requires the construction of a second complete set of constraints to reduce the flow beginning in

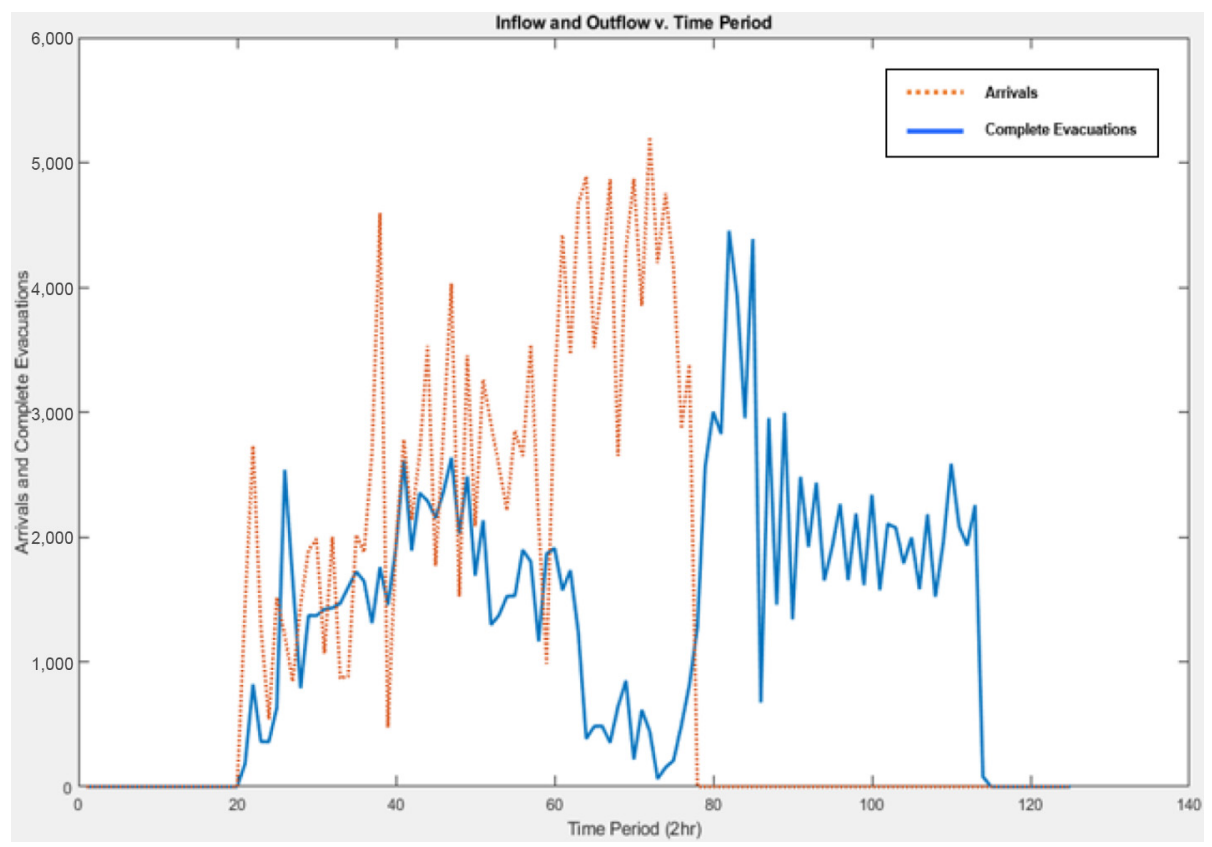

Modeling and transportation planning 西

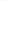

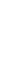


JDAL

4,1

62

a particular time period. Building on the results of the initial case study and factoring in the loss of assets, Figure 9 depicts the revised schedule performance. Comparing against Table 4, total evacuation time slips from 179.5 to 186.5 hours with the loss, and so $2 \mathrm{ID}$ would need to look to shift assets to complete the mission within their requirements.

5.3.3 Disruption 3. Arc closures. As with the mandatory closure of an AP on a specified day, the closure of any arc is easily accounted for by the adjustment of its upper bound. Within this scenario, the bus arcs connecting AP1 at Camp Casey to Busan Station, the Reception Center and the SPOD have been disrupted as a result of the military conflict, beginning on day 4 . At this point, to adjust the model to account for the constraint, an upper bound of zero can be applied to the bus arcs from AP1 beginning in time period 192, or day 4 . With this constraint, the model will schedule assets around these closed arcs and still seek to minimize the total time of the evacuation. Figure 9 and Table 4 highlight the complete effect of all disruptions, arc closures, the attrition of train assets, and the irregular arrival profile.

In total, this disrupted evacuation fails to meet a number of the requirements established in the planning portion of this case study, and therefore to satisfy those demands 2ID needs to determine what additional assets are required to achieve the required schedule performance.

\subsection{Complete case study solution}

The disruptions applied to an evacuation within this case study illuminate the structural challenges present in keeping schedule performance to within an acceptable range. That said, this model provides a fast and expedient method to analyze and adjust the plan to meet mission requirements in response to disruptions. For the purposes of this evacuation scenario and considering the disruptions, $2 \mathrm{ID}$ would need to source 42 additional buses following the loss of

Figure 9.

(color online) Inflow and outflow v. time of the complete case study solution

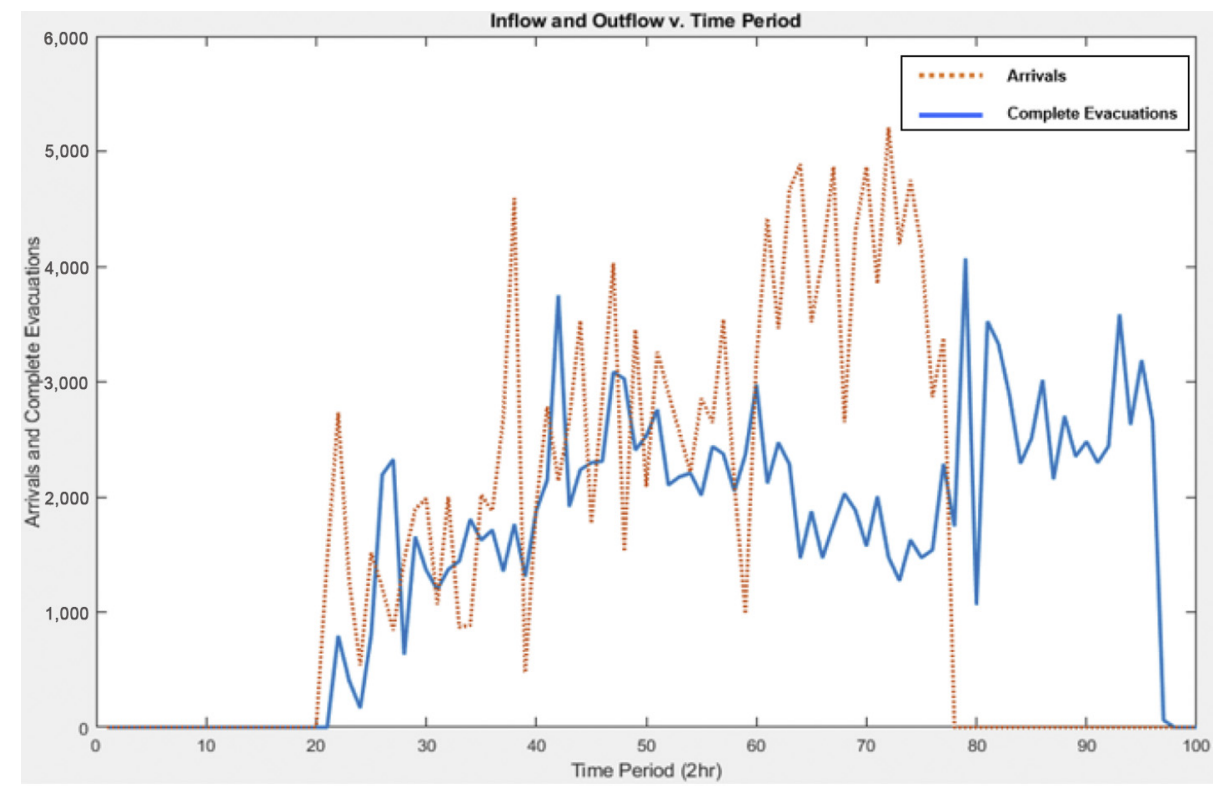

Note: Visually, the effects of changing the arrival profile are apparent in the figure and it is also clear that the operation ends before the specified time limit 


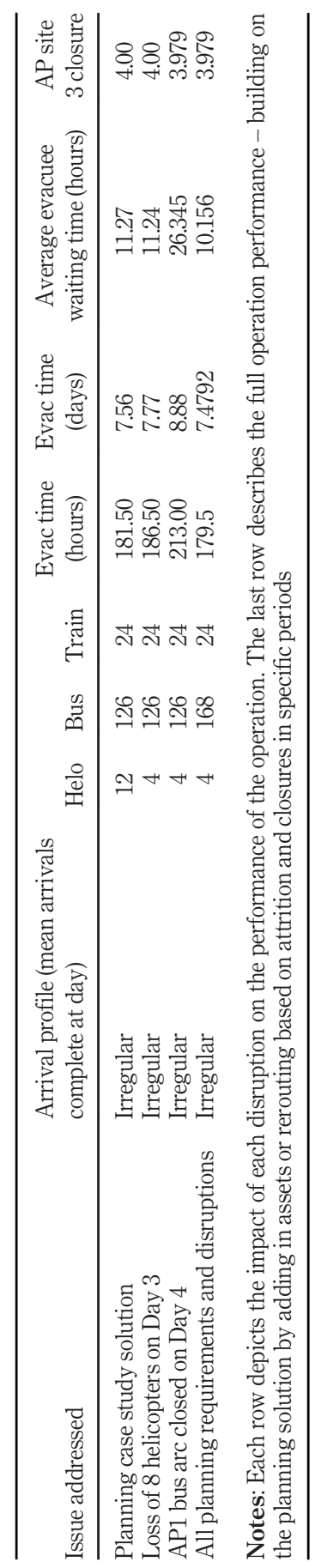

Modeling and transportation planning

63

Table 4

Progression of the disruptions case study 
$\underset{4,1}{\mathrm{JDAL}}$

64

8 helicopters and the closure of bus routes out of AP1 to keep the schedule on track to meet the required metrics. Table 4 shows the accumulating effects of the disruptions and shows the final schedule performance factoring the additional assets that are required to get the schedule within the acceptable performance levels. The impact of these disruptions on schedule performance is considerable and may point to some inherent weakness in the evacuation network itself that $2 \mathrm{ID}$ could look to design around moving forward.

\section{Conclusion}

The primary goal of this work was to model the noncombatant transportation network in South Korea and devise an intelligent method for the allocation of transportation assets to facilitate a timely evacuation. The next objective was to analyze the performance of the model under various circumstances and identify ways to improve or respond to additional planning factors or address issues that could arise during the execution of the mission.

Viable asset allocation schedules were created through the development and application of a time-staged network flow model coupled with a Poisson arrival process which facilitates an understanding of the required time and resources complete evacuation. Depending on the scenario, it is possible to calculate, and subsequently verify, how adding to or subtracting from the fleet size of a particular transportation mode impacts the evacuation time. It is possible to bound the model in such a way as to close APs early and schedule around the closure of specific routes and nodes in response to disruptions. And it has been shown how affecting the profile of arrivals can be used to limit waiting time through the system. The procedures described in this paper provide 2ID, and similarly situated GCCs, with a working methodology that can be applied to their circumstances to successfully allocate and schedule resources to complete noncombatant evacuation missions.

This work contributes to military NEO applications and the literature in a few ways. It seeks to improve the decision-making and resource allocation methodology used by 2ID in South Korea, and addresses an obvious need in that instance. But broadly, this work is productive for noncombatant operations as a mission set. This work has clear application in the Baltic States and Germany, where similar population levels and infrastructure require intelligent resource allocation in the event of an evacuation. And looking inward, military support to natural disaster evacuations within the USA provides another application for this model, albeit with different motivating circumstances. The formulation of this problem is based on the optimization of tactical decisions within an evacuation mission. This is unique in that previous works are planning-oriented and focus on what resources can be prepositioned, what routes and locations will be used and how can we optimize an evacuation on the front end. This work constructs process to use in near-real time to conduct evacuation optimization in response to arrivals and a fluid transportation infrastructure where assets are re-allocated and adjusted throughout a mission using situation reports. To summarize, this work contributes to the military understanding and execution of NEO missions by using optimization tools to make tactical decisions within the execution of an operation.

The recommended course of action for 2ID is to use the model and scheduler during the annual South Korea NEO simulations: Operations Courageous Channel and Ulchi Freedom Guardian. The transportation assets can be allocated according the model's solution and updated in real time as reports of arrivals come into system and disruptions occur. Through iteration, that process would likely reveal other areas to improve and streamline the function of the complete system so that 2ID could be better prepared to respond and facilitate a successful operation in the event of a real world NEO.

Noncombatant evacuation operations in South Korea present a complex problem with many intriguing areas for future research. An exploration of the sensitivity of this model to changing 
arrival rate parameters based on proximity to North Korea, variable travel times to account for traffic and congestion, and accounting for mis-routed transportation assets would all be of interest in future work. Study of the evacuation network itself would also be invaluable; critical nodes and specific routes within the schedule could be identified to reduce risk and formulate a more robust solution, better prepared to avoid and manage disruptions. This a rich and meaningful problem with many opportunities for further investigation.

Modeling and transportation planning

\section{References}

Abdelgawad, H., Abdulhai, B. and Wahba, M. (2010), "Multiobjective optimization for multimodal evacuation", Transportation Research Record: Journal of the Transportation Research Board, Vol. 2196 No. 1, pp. 21-33.

Altay, N. and Green, W.G. (2006), "OR/MS research in disaster operations management", European Journal of Operational Research, Vol. 175 No. 1, pp. 475-493.

Aringhieri, R., Bruni, M.E., Khodaparasti, S. and van Essen, J.T. (2017), "Emergency medical services and beyond: addressing new challenges through a wide literature review", Computers and Operations Research, Vol. 78, pp. 349-368.

Bertsimas, D. and Ng, Y. (2019), "Robust and stochastic formulations for ambulance deployment and dispatch", European Journal of Operational Research, Vol. 279 No. 2, pp. 557-571.

Bish, D.R. (2011), "Planning for a bus-based evacuation”, OR Spectrum, Vol. 33 No. 3, pp. 629-654.

Chalmet, L.G., Francis, R.L. and Sanders, P.B. (1982), "Network models for building evacuation”, Management Science, Vol. 28 No. 1, pp. 86-105.

Chen, D., Batson, R.G. and Dang, Y. (2010), Applied Integer Programming, Wiley, Hoboken, NJ, 252-256.

Choi, W., Hamacher, H.W. and Tufekci, S. (1988), "Modeling of building evacuation problems by network flows with side constraints", European Journal of Operational Research, Vol. 35 No. 1, pp. 98-110.

CIA (2019a), "South Korea transportation map”, available at: www.cia.gov/library/publications/resources/ cia-maps-publications/map-downloads/SouthKorea_Transportation.pdf, (accessed 3 October 2019).

CIA (2019b), "The world factbook: Korea, South", available at: www.cia.gov/library/publications/theworld-factbook/geos/ks.html, (accessed 3 October 2019).

Dhamala, T.N. (2014), "A survey of models and algorithms for discrete evacuation planning network problems”, Journal of Industrial and Management Optimization, Vol. 11 No. 1, pp. 265-289.

Dix, J., Munoz-Avila, H., Nau, D. and Zhang, L. (2002), "Theoretical and empirical aspects of a planner in a multi-agent environment”, Logics in Artificial Intelligence, Vol. 8 No. 24, pp. 173-185.

Fulton, L.V., Lasdon, L.S., McDaniel, R.R. and Coppola, M.N. (2010), "Two-stage stochastic optimization for the allocation of medical assets in steady state combat operations", Journal of Defense Modeling and Simulation, Vol. 7 No. 1, pp. 25-37.

Galindo, G. and Batta, R. (2013), "Review of recent developments in OR/MS research in disaster operations management”, European Journal of Operational Research, Vol. 230 No. 2, pp. 201-211.

Gan, H., Richter, K., Shi, M. and Winter, S. (2016), "Integration of simulation and optimization for evacuation planning”, Simulation Modelling Practice and Theory, Vol. 67, pp. 59-73.

Germain, J.T. (1997), “Operation Silver Wake”, Marine Corps Gazette, Vol. 81 No. 9, pp. 64-66.

Goerigk, M. and GrüN, B. (2014), “A robust evacuation model with delayed scenario information”, Or Spectrum, Vol. 36 No. 4, pp. 923-948.

Goerigk, M., Deghdak, K. and T'Kindt, V. (2015), “A two-stage robustness approach to evacuation planning with buses", Transportation Research Part B, Vol. 78, pp. 66-82.

Gregg, A.N. (2010), "Optimizing crisis action planning in the noncombatant evacuation setting", Master's thesis, Air Force Institute of Technology, available at: https:/apps.dtic.mil/dtic/tr/ fulltext/u2/a546413.pdf 


\section{JDAL 4,1}

Hamacher, H.W. and Tjandra, S.A. (2002), "Mathematical modelling of evacuation problems: a state of the art", in Schrekenberg, M. and Sharma, S.D. (Eds), Pedestrian and Evacuation Dynamics, Springer, Berlin, pp. 227-266.

Jarvis, J.J. and Ratliff, H.D. (1982), "Some equivalent objectives for dynamic network flow problems", Management Science, Vol. 28 No. 1, pp. 106-109.

Joint Doctrine Group (2010), "Joint Publication (JP) 3-68 Noncombatant Evacuation Operations, 12 2010", Washington, DC, available at: www.apd.army.mil/epubs/DR_pubs/DR_a/pdf/web/jp3_68.pdf, (accessed 16 May 2017),

Junkins, J.L. (2012), "Noncombatant evacuation operations (NEO) decision-making process effects on efficiency", Research Report, Air War College, Air University.

Karbovskii, V., Voloshin, D., Karsakov, A., Bezgodov, A. and Zagarskikh, A. (2015), "Multiscale agentbased simulation in large city areas: Emergency evacuation use case", Procedia Computer Science, Vol. 51, pp. 2367-2376.

Kawsar, L.A., Ghani, N.A., Kami, A.A. and Mustafa, A. (2019), "Optimization based controlled evacuation”, Journal of Intelligent Transportation Systems, Vol. 23 No. 5, pp. 477-498.

Kearby, J. (2019), "Time-Staged network flow modeling and transportation planning for noncombatant evacuation operations in South Korea", Master's thesis, Operations Research Graduate Program, North Carolina State University, Raleigh, NC, available at: www.lib.ncsu.edu/resolver/1840.20/36331.

Kisko, T.M. and Francis, R.L. (1985), "EVACNET+: a computer program to determine optimal building evacuation plans", Fire Safety Journal, Vol. 9 No. 2, pp. 211-220.

KTX (2018), "KTX High-Speed train lines and travel times", available at: https://rail.ninja/train/ktxhigh-speed-train, (accessed 19 September 2018).

Kuchell, D. (2013), "Analyzing noncombatant evacuation operations using discrete event simulation", Pasupathy, R., Kim, S.H., Tolk, A., Hill, R. and Kuhl, M.E. (Eds), Proceedings of the 2013 Winter Simulation Conference, pp. 2751-2761.

Kulshrestha, A., Lou, Y. and Yin, Y. (2014), "Pick-up locations and bus allocation for transit-based evacuation planning with demand uncertainty", Journal of Advanced Transportation, Vol. 48 No. 7, pp. 721-733.

Lakshay, N. and Bolia, B. (2019), "Operating strategies of buses for mass evacuation”, Safety Science, Vol. 111, pp. 167-178.

Law, A. (2007), Simulation Modeling and Analysis, 4 ed., McGraw-Hill, Boston, MA, 643-655.

Lim, G.J., Zangeneh, S., Baharnemati, M.R. and Assavapokee, T. (2012), "A capacitated network flow optimization approach for short notice evacuation planning", European Journal of Operational Research, Vol. 223 No. 1, pp. 234-245.

LTC Erickson (2018), "LTC N. Erickson, C5 plans officer, 2ID ROK-US combined. 2ID - NEO transportation model, 5", Email communications from 9-23 May 2018.

Lu, Q., George, B. and Shekhar, S. (2005), "Capacity constrained routing algorithms for evacuation planning: a summary of results", In Medeiros, C.B., Egenhofer, M. and Bertino, E., editors, Advances in Spatial and Temporal Databases, pages 291-307. Springer, Berlin, Germany.

Lu, Q., Huang, Y. and Shekhar, S. (2003), "Evacuation planning: a capacity constrained routing approach", in Chen, H., Miranda, R., Zeng, D.D., Demchak, C., Schroeder, J. and Madhusudan, T. (Eds), Intelligence and Security Informatics, Springer, Berlin, pp. 111-125.

Murray-Tuite, P. and Wolshon, B. (2013), "Evacuation transportation modeling: an overview of research, development, and practice", Transportation Research Part C: Emerging Technologies, Vol. 27, pp. 25-45.

Olsen, C.M. (2011), "Simulation study of evacuation control center operations analysis. Master's", thesis, Air Force Institute of Technology, available at: https:/apps.dtic.mil/dtic/tr/fulltext/u2/a546629.pdf

Park, M.H. (2015), "A research on the Republic of Korea army barracks layout design to minimize the maximum egress times using evacuation planning program (EVACNET). master's ", thesis, 
Department of Industrial and Systems Engineering, North Carolina State University, Raleigh, available at: www.lib.ncsu.edu/resolver/1840.16/10394

Praveen, E., Siddharth, S. and Catherine, M. (2010), "Development of a large-scale traffic simulation model for hurricane evacuation - methodology and lessons learned”, Natural Hazards Review, Vol. 11 No. 4, pp. 127-139.

Robbins, M.J., Jenkins, P.R., Bastian, N.D. and Lunday, B.J. (2018), "Approximate dynamic programming for the aeromedical evacuation dispatching problem: Value function approximation utilizing multiple level aggregation”, Omega, In Press, Published Online 20 Dec

Modeling and transportation planning 2018.

Saadatseresht, M., Mansourian, A. and Taleai, M. (2009), "Evacuation planning using multiobjective evolutionary optimization approach", European Journal of Operational Research, Vol. 198 No. 1, pp. 305-314.

Sayyady, F. and Eksioglu, S.D. (2010), "Optimizing the use of public transit system during no-notice evacuation of urban areas", Computers and Industrial Engineering, Vol. 59 No. 4, pp. $488-495$.

Scheer, M.A. (2011), "Noncombatant evacuation operations in EUCOM. Master's ", thesis, Air Force Institute of Technology, available at: https://apps.dtic.mil/dtic/tr/fulltext/u2/a546413.pdf.

Shin, Y., Kim, S. and Moon, I. (2019), "Simultaneous evacuation and entrance planning in complex building based on dynamic network flows", Applied Mathematical Modelling, Vol. 73, pp. 545-562.

Song, Y. and Yan, X. (2016), "A method for formulizing disaster evacuation demand curves based on SI model", International Journal of Environmental Research and Public Health, Vol. 13 No. 10, pp. 986 .

Sumner, J.E. and Zahn, E.A. (1996), "A simulation of the evacuation of american citizens with an objectoriented animated model”, Charnes J.M, Morrice D.J., Brunner D.T. and Swain J.J., (Eds). Proceedings of the 1996 Winter Simulation Conference, pp. 967-974.

Sung-Jin, C. (2016), "Number of cars in South Korea nears 21 million”, Korea Times, available at: www. koreatimes.co.kr/www/news/biz/2016/01/123_195662.html, (accessed 6 May 2018)

United States Department of State (2018), Seoul Annual F-77 Data, 3.

Vigo, D. and Toth, P. (2014), Vehicle Routing, Society for Industrial and Applied Mathematics, pp. 37-57.

Washington, J.W. (2015), “Operation Frequent Wind”, Marine Corps Gazette, Vol. 99 No. 5, pp. 50-54.

Waze (2018), "Waze live traffic and directions", available at: https://waze.com/livemap, (accessed 19 September 2018).

Wolsey, L.A. (1998), Integer Programming, Wiley-Interscience, New York, NY, 38-41.

Wright, P.D., Liberatore, M.J. and Nydick, R.L. (2006), "A survey of operations research models and applications in homeland security", Interfaces, Vol. 36 No. 6, pp. 514-529.

Yamada, T. (1996), "A network flow approach to a city emergency evacuation planning", International Journal of Systems Science, Vol. 27 No. 10, pp. 931-936.

Yuan, F., Han, L.D., Chin, S. and Hwang, H. (2006), "Proposed framework for simultaneous optimization of evacuation traffic destination and route assignment", Transportation Research Record: Journal of the Transportation Research Board, Vol. 1964 No. 1, pp. 50-58.

Yuan, F. (2005), "A proposed framework for simultaneous optimization of evacuation traffic destination and route assignment", $\mathrm{PhD}$ thesis, The University of Tennessee, Knoxville, TN, available at: https://trace.tennessee.edu/utk_graddiss/2384

Zhang, S. Parr, A., Jiang H. and Wolshon, B. (2015), "Optimization model for regional evacuation transportation system using macroscopic productivity function”, Transportation Research Part $B$, Vol. 81, pp. 616-630. 


\section{JDAL 4,1}

68
Figure A1.

Example report showing next three days of evacuee movements by mode of transportation

\section{Appendix}

The coupling of the optimization model with the vehicle routing procedure post-processing the solution provides two different useful operational reporting capabilities. Obviously, by definition the solution provides immediate visibility into evacuee flow by mode and by location over time. This can be aggregated, as demonstrated in Figure A1, to product a high-level overview of the schedule suitable for certain military echelons.

However, this still requires units to assign these trips from the schedule to individual assets (including pilots, drivers, etc.). Fortunately, the vehicle routing procedure produces this level of detail which is nested with the aggregate view. This provides detailed instructions for individual assets and a summary utilization report, depicted by Figure A2, showing when each asset will be in operation. This also permits visualizing downtime for maintenance planning and assists in being able to quickly redirect assets as things inevitably change throughout a day. Other examples of visualizations may be found in Kearby (2019, p. 27, 29, 31-32).

\begin{tabular}{|c|c|c|c|c|c|c|c|c|}
\hline \multicolumn{9}{|c|}{ NEO Transportation Schedule Overviev } \\
\hline \multirow{20}{*}{ CH-47 Trips } & \multirow[b]{2}{*}{ Starting Location } & \multirow[b]{2}{*}{ Ending Location } & \multicolumn{2}{|c|}{ Day 1 Trip Totals } & \multicolumn{2}{|c|}{ Day 2 Trip Totals } & \multicolumn{2}{|c|}{ Day 3 Trip Totals } \\
\hline & & & 0000-1159 & $1200-2359$ & 0000-1159 & $1200-2359$ & $0000-1159$ & $1200-2359$ \\
\hline & AP-Camp Casey & AP-Camp Red Cloud & & & & & & \\
\hline & AP.CampCasey & AP.Yongsan & & & & & & \\
\hline & AP-Camp Casey & AP-Camp Humphreys & & & & & & \\
\hline & AP.Camp Casey & Busan Train Station & & & 4 & & & \\
\hline & AP.Camp Casey & Reception Center & & & & & & \\
\hline & AP.Camp Casey & A,SPOD & & & & & & \\
\hline & AP.Camp Red Cloud & AP. Yongsan & & & 3 & & & \\
\hline & AP.Camp Red Cloud & AP.Camp Humphreys & & & & & & \\
\hline & AP. Camp Red Cloud & Busan Train Station & & & & & & \\
\hline & AP.Camp Red Cloud & Reception Center & & & 4 & 1 & & 6 \\
\hline & AP.Camp Red Cloud & A.SPPOD & & & & & & \\
\hline & AP-Yongsan & AP-Camp Humphreys & & & & & & 1 \\
\hline & AP. Yongsan & Busan Train Station & & & 4 & & & \\
\hline & AP-Yongsan & Reception Center & & & & & 5 & 9 \\
\hline & AP-Yongsan & A.SPPD & & & & & & \\
\hline & AP-Camp Humphreys & Busan Train Station & & & 1 & & 20 & \\
\hline & AP.Camp Humphreys & Reception Center & & & 7 & & 15 & 10 \\
\hline & AP-Camp Humphreys & A.ISPOD & & & & & & \\
\hline \multirow{28}{*}{ Bus Trips } & \multirow{2}{*}{ Starting Location } & \multirow{2}{*}{ Ending Location } & \multicolumn{2}{|c|}{ Day 1 Trip Totals } & \multicolumn{2}{|c|}{ Day 2 Trip Totals } & \multicolumn{2}{|c|}{ Day 3 Trip Totals } \\
\hline & & & 0000-1159 & $1200-2359$ & 0000-1159 & $1200-2359$ & $0000-1159$ & $1200-2359$ \\
\hline & AP. Casey & Dongducheon Station & & & 8 & 14 & 15 & \\
\hline & AP.Casey & Uleongbu Station & & & 2 & & 6 & \\
\hline & AP.Casey & Seoul Station & & & & & & \\
\hline & AP-Casey & Busan Station & & & & & & \\
\hline & AP. Casey & Reception Center & & & 4 & & 4 & \\
\hline & AP.Casey & A.ISPOD & & & & & & \\
\hline & AP-Red Cloud & Ureongbu Station & & & 9 & 15 & 16 & \\
\hline & AP-RedCloud & Seoul Station & & & 1 & & 5 & \\
\hline & AP-RedCloud & Busan Station & & & & & & \\
\hline & AP-RedCloud & Pecesption Center & & & 8 & 6 & 4 & \\
\hline & AP-Red Cloud & A.PPOD & & & & & & \\
\hline & AP.Yongsan & Seoul Station & & & 12 & 15 & 18 & \\
\hline & AP-Yongsan & Busan Station & & & & & & \\
\hline & AP. Yongsan & Recoption Center & & & & & 5 & \\
\hline & AP-Yongsan & A.SPPOD & & & & & & \\
\hline & AP-Humphreys & Pyeongtaek Station & & & 3 & 3 & 8 & \\
\hline & AP-Humphreys & Busan Station & & & & & & \\
\hline & AP. Humphreys & Reception Center & & & 9 & 19 & 9 & \\
\hline & AP-Humphreys & A.SPPOD & & & & & & \\
\hline & AP - Jamsil Sradium & Seoulstation & & & & & & \\
\hline & A.P - Jamsil Stadium & Busan Station & & & & & & \\
\hline & AP.Jamsil Stadium & Reception Center & & & 4 & 3 & 5 & \\
\hline & AP. Jamsil Stadium & AISPOD & & & & & & \\
\hline & Busan Station & Reception Center & & & 7 & 25 & 24 & 1 \\
\hline & Busan Station & AISPOD & & & & & & \\
\hline & Reception Center & A.ASPOD & & & 16 & 24 & 170 & 149 \\
\hline \multirow{9}{*}{ Train Trips } & \multirow{2}{*}{ Starting Location } & \multirow{2}{*}{ Ending Location } & Dag 1 Tri & p Totals & Dag 2 Tr & ip Totals & Dag 3 Tr & ip Totals \\
\hline & & & 0000-1159 & $1200-2359$ & $0000-1159$ & $1200-2359$ & $0000-1159$ & $1200-2359$ \\
\hline & AP - Jamsil Skadium & Seoul Station & & & & & & \\
\hline & Dongducheon Station & Ureongbu Station & & & 1 & & 1 & 2 \\
\hline & Dongducheon Station & Secoulstation & & & & & & \\
\hline & Uijeongbu Station & Seoul Station & & & & 1 & & 6 \\
\hline & Pyeongeaek Station & Asan Station & & & 3 & & & 1 \\
\hline & Asan Station & Busan Station & & & 3 & & & \\
\hline & Seroul Station & Busan Station & & & 1 & 7 & 2 & 2 \\
\hline
\end{tabular}




\section{List of acronyms}

$\begin{array}{ll}\text { 2ID } & =\text { 2nd Infantry Division; } \\ \text { AP } & =\text { Assembly Point; } \\ \text { A/SPOD } & =\text { Air/Sea Port of Debarkation; } \\ \text { DoD } & \text { = Department of Defense; } \\ \text { DOS } & =\text { Department of State; } \\ \text { GCC } & =\text { Geographic Combatant Command; } \\ \text { HN } & =\text { Host Nation; } \\ \text { MEDEVAC } & =\text { Military Aeromedical Evacuation; } \\ \text { MILP } & =\text { Mixed Integer Linear Program; } \\ \text { NEO } & =\text { Noncombatant Evacuation Operation; } \\ \text { TCN } & \text { Third-Country National; and } \\ \text { USG } & =\text { US Government. }\end{array}$

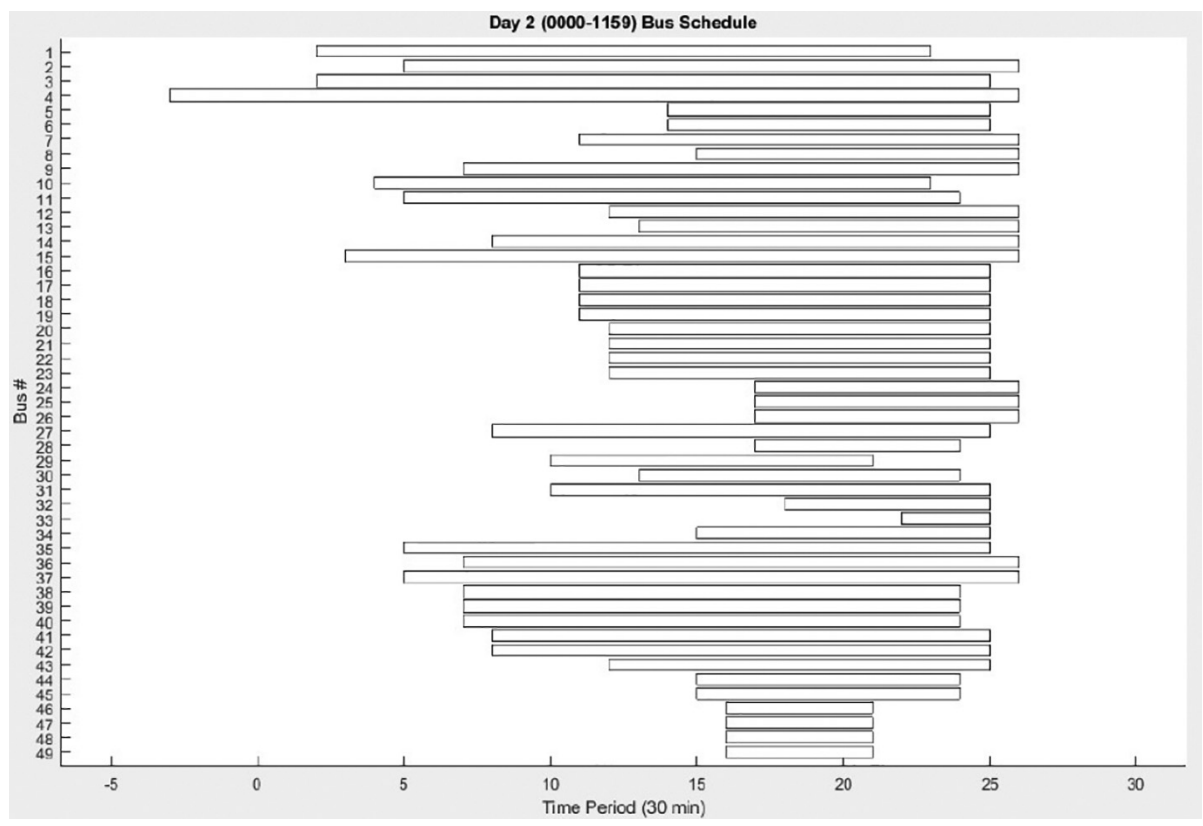

Figure A2.

Example utilization report for buses on

Day 2

Corresponding author

John A. Kearby can be contacted at: jkearby@ncsu.edu

For instructions on how to order reprints of this article, please visit our website: www.emeraldgrouppublishing.com/licensing/reprints.htm

Or contact us for further details: permissions@emeraldinsight.com 